\title{
Human gastric B cell responses can be induced by intestinal immunisation
}

\author{
M Quiding-Järbrink, H Lönroth, I Ahlstedt, J Holmgren, A-M Svennerholm
}

\begin{abstract}
Background-In a previous study, we found that oral vaccination induces strong B cell responses in the stomach of Helicobacter pylori infected but not of uninfected individuals. In this study, we have evaluated the possibility of inducing gastric immune responses in $H$ pylori infected volunteers by intestinal and gastric immunisation.
\end{abstract}

Methods-H pylori infected subjects were given two doses of an inactivated cholera vaccine, either intestinally via an endoscope approximately $30 \mathrm{~cm}$ distal to the pylorus sphincter or intragastrically as small droplets applied directly onto the stomach mucosa. Uninfected individuals received the vaccine by standard oral procedure. Vaccine specific antibody secreting cells in antral and duodenal biopsies were detected by the enzyme linked immunospot assay technique before and seven days after the second immunisation. Results-Intestinal immunisations resulted in induction of vaccine specific gastric IgA secreting cells in five of eight volunteers. This immunisation schedule also gave rise to specific duodenal antibody secreting cells in seven of eight individuals. Local gastric immunisation resulted in the induction of specific $B$ cells in the gastric mucosa of four of eight volunteers. Gastric antigen application also resulted in $B$ cell responses in the duodenum in all volunteers. Uninfected volunteers receiving the vaccine perorally responded in the duodenum but not in the stomach.

Conclusions-H pylori infection increases the ability of the gastric mucosa to serve as an expression site for intestinally induced $B$ cell responses. These findings are of importance when designing a therapeutic $H$ pylori vaccine, and based on our results such a vaccine can be delivered along the whole upper gastrointestinal tract.

(Gut 2001;49:512-518)

Keywords: Helicobacter pylori; vaccine; stomach; B cell; lymphocyte trafficking

Correspondence to: Dr M Quiding-Järbrink, Göteborg University, Department of Medical Microbiology and Immunology, Guldhedsgatan 10A, S-413 46 Göteborg Sweden.

marianne.quiding@

microbio.gu.se

Accepted for publication 29 March 2001

Infection with the Gram negative bacterium Helicobacter pylori is associated with the development of active chronic gastritis, duodenal ulcer (DU), and primary gastric lymphoma. ${ }^{1}$ Infected individuals develop active chronic gastritis, characterised by a dense infiltration of neutrophils and lymphocytes in the gastric mucosa. In many individuals, gastritis is accompanied by the development of organised lymphoid follicles containing $B$ and $T$ cell areas in the gastric mucosa. ${ }^{3}$ Another feature of the immune response to $H$ pylori infection is the production of specific IgA antibodies which can be detected both systemically and in gastric tissues. ${ }^{4-8}$ Whether gastric IgA secreting cells are activated and differentiate locally in the gastric mucosa or rather originate from the organised lymphoid inductive sites in the intestine is not yet known. In spite of the specific immune responses, most individuals are not able to clear the infection, which is usually lifelong.

A number of animal studies have demonstrated that oral immunisation with various $H$ pylori antigens together with mucosal adjuvants may result in protection against subsequent bacterial challenge. ${ }^{9-14}$ Protection by therapeutic immunisation of mice with Helicobacter infections has also been achieved, ${ }^{15-17}$ even though such immunisation usually does not lead to sterilising immunity. In some of these studies, ${ }^{12-14}$ protection correlated with mucosal antibody production but to date the effector mechanisms resulting in clearance of $\mathrm{H}$ pylori after immunisation still remain largely unknown. As $H$ pylori is not invasive, but resides on the gastric epithelial surface and in gastric mucus, local production of secretory IgA antibodies is potentially important for bacterial eradication. A role for secretory IgA in protection is suggested by studies of passive immunity, both in humans and experimental animals. ${ }^{18-20}$ On the other hand, it has recently been reported that antibody deficient mice and fully immunocompetent mice are protected to the same extent against $H$ pylori challenge following oral immunisation. ${ }^{21}$

In a previous study, we examined the possibility of inducing specific IgA responses in the human gastric mucosa using an orally inactivated cholera vaccine as a model immunogen. ${ }^{22}$ We demonstrated that the oral vaccination resulted in vaccine specific antibody secreting cell (ASC) responses in the gastric mucosa of $H$ pylori infected individuals whereas uninfected individuals failed to mount detectable B cell responses in the stomach. As both groups of vaccinees had similar frequencies of vaccine specific ASC in the duodenal mucosa, we speculated that the gastric ASC response in $H$ pylori infected volunteers might
Abbreviations used in this paper: ASC, antibody secreting cells; BSA, bovine serum albumin; CTB, cholera toxin B subunit; DU, duodenal ulcer; ELISPOT, enzyme linked immunospot assay; HLO, Helicobacter-like organism; MNC, mononuclear cells. 
result either from increased gastric antigen uptake and presentation or from increased migration of intestinally activated $B$ cells into the stomach. To evaluate these hypotheses further, and to explore how gastric antibody responses may be induced, we have given inactivated cholera vaccine to $H$ pylori infected volunteers, either intestinally or intragastrically, and recorded the resulting immune responses in the gastric and duodenal mucosae as well as in the circulation.

\section{Materials and methods VOLUNTEERS}

The study was performed following approval from the human research ethics committee of the Medical Faculty, Göteborg University, and all volunteers gave informed consent to participate. Seven $H$ pylori infected individuals with gastrointestinal symptoms, two of whom had scars after a previous DU, were recruited among patients attending the gastroenterology unit at Sahlgrenska University Hospital, Göteborg. Nine asymptomatic $H$ pylori carriers were identified by serological screening of healthy blood donors. ${ }^{23}$ None of the infected volunteers had an active ulcer or was on any medication for at least one week preceding the study. In addition, 12 healthy uninfected individuals without any gastrointestinal disorders were recruited. Before enrolment, $H$ pylori infection was assessed in all volunteers by serology or urea breath test. ${ }^{23}$ Furthermore, $H$ pylori status was always confirmed by culture of gastric biopsies (see below). All volunteers received two doses of an oral cholera vaccine (Dukoral; SBL Vaccin, Stockholm, Sweden $)^{24}$ two weeks apart; each dose consisted of $1 \mathrm{mg}$ of recombinant cholera toxin $\mathrm{B}$ subunit (CTB) and $10^{11}$ killed Vibrio cholerae organisms.

INTESTINAL IMMUNISATION

Eight $H$ pylori infected volunteers (aged 33-58 years; four females; five asymptomatic carriers, two with dyspeptic symptoms, and one patient previously suffering from DU) received the vaccine locally in the small intestine. This was done during gastroduodenoscopy, introducing the endoscope down to the level of the ligament of Treitz-that is, approximately $30 \mathrm{~cm}$ distal to the pylorus sphincter-with the patient in the left lateral position. The vaccine was introduced through a $1.6 \mathrm{~mm}$ catheter and administered in $15 \mathrm{ml}$ of physiological saline, followed by $5 \mathrm{ml}$ of saline to rinse the catheter.

To ensure that only minimal amounts of vaccine were refluxed into the stomach after intestinal deposition, the vaccine was administered together with ${ }^{13} \mathrm{C}$ labelled polyethyleneglycol in pilot experiments. These experiments showed that only $2 \%$ of the administered polyethyleneglycol, $0.05 \%$ of CTB, and $<1 \%$ of the whole cell component were recovered in the total amount of gastric juice collected from these subjects by a nasogastric tube within the first two hours after immunisation. Gastric aspirates collected directly after each duodenal immunisation consistently contained less than $0.01 \%$ of the total amount of CTB given, and less than $1 \%$ of the whole cell component.
INTRAGASTRIC IMMUNISATION

Another group of eight $H$ pylori infected volunteers (aged 36-61 years; two females; four asymptomatic carriers, three with dyspeptic symptoms, and one previous DU patient) as well as four healthy uninfected individuals (aged 22-39 years; one female) were immunised twice intragastrically. The vaccine $(4 \mathrm{ml})$ was directly distributed as small droplets over the antral mucosa with the patient in the left lateral position using a $1.6 \mathrm{~mm}$ catheter through the endoscope. This made it possible to deliver the droplets accurately and to ensure by inspection that the fluid was spread over the mucosa and absorbed almost instantly. Subjects receiving intragastric deposition of vaccine were treated with a daily dose of $120 \mathrm{mg}$ of omeprazole (Losec) during the last two days prior to vaccination to reduce gastric output.

ORAL IMMUNISATION

For comparative purposes, eight healthy uninfected individuals (aged 21-35 years; three females) received the vaccine by the standard peroral procedure - that is, as a drink with the vaccine in $150 \mathrm{ml}$ of a neutralising bicarbonate buffer. ${ }^{24}$ In addition to the standard vaccination protocol, ${ }^{24}$ these volunteers also received $1.5 \mathrm{~g}$ of acetylsalicylic acid during the last three days before their first vaccination. This was done in order to create a mild gastric inflammation and make their gastric mucosal microenvironment more similar to that of $H$ pylori infected individuals at the time of the first antigen delivery. ${ }^{25}$

\section{SPECIMEN COLLECTION}

Heparinised venous blood and serum were collected from all volunteers one week before the first and one week after the second immunisation. At the same time points, 11 antral and 14 duodenal biopsies, $2 \mathrm{~mm}$ in diameter and encompassing the epithelium and lamina propria, were also collected from each of the volunteers under local anaesthesia. One antral and four duodenal biopsies were fixed in $4 \%$ formalin, stained with haematoxylin, and examined by an experienced histopathologist who was unaware of the subjects' clinical symptoms and immunisation schedule. Gastritis and the presence of Helicobacter-like organisms (HLO) were graded from 0 to 3 (none, mild, moderate, or severe), according to the upgraded Sydney system. ${ }^{26}$ Gastric aspirates were put on ice and adjusted to $\mathrm{pH} 6-8$, enzymatic degradation was inhibited, ${ }^{7}$ and the aspirates stored at $-70^{\circ} \mathrm{C}$ until ELISA analyses were performed.

ISOLATION OF MONONUCLEAR CELLS (MNC) AND DETECTION OF ASC

Peripheral blood MNC were collected by isopycnic gradient centrifugation on FicollHypaque (Pharmacia, Uppsala Sweden). Gastric and duodenal lymphocytes were isolated from the remaining biopsies by short term enzymatic digestion using thermolysine and collagenase. ${ }^{22}{ }^{27}$ Before enzymatic digestion, an aliquot of the fragmented tissue was cultured on Skirrow blood agar plates containing 10\% 
horse blood for three days under microaerophilic conditions to confirm the $H$ pylori status of the volunteers.

The frequencies of ASC in the cell suspensions isolated from blood, antrum, and duodenum were determined in double colour enzyme linked immunospot (ELISPOT) assays using ganglioside GM1 (Sigma) followed by recombinant CTB as coating antigen. ${ }^{22}{ }^{28}$ Control assays were performed in parallel in wells coated with bovine serum albumin (BSA), and the total frequencies of IgA and IgG secreting cells, irrespective of specificity, were determined in wells coated with goat antibodies to the $\mathrm{F}(\mathrm{ab})_{2}$ fragment of human IgG (Jackson ImmunoResearch Laboratories, Inc., West Grove, Pennsylvania, USA).

Intestinal MNC were plated at $10^{4}$ and $2 \times 10^{3}$ MNC per ELISPOT well, gastric MNC at $4 \times 10^{4}$ and $10^{4}$ cells per well, and blood MNC at $10^{6}$ and $2 \times 10^{5}$ cells per well in duplicate. The presence of two or more specific ASC in the wells with the highest cell concentration was regarded as a significant ASC response, corresponding to 200 spots per $10^{6} \mathrm{MNC}$ for intestinal cells, 50 spots per $10^{6} \mathrm{MNC}$ for gastric cells, and 2 spots per $10^{6} \mathrm{MNC}$ for blood cells. These cut off levels represent the mean $+3 \mathrm{SD}$ of IgA spot forming cells in the duodenum of non-immunised volunteers. A twofold or larger increase in ASC frequencies, after adjusting for any changes in total IgA secreting cell frequencies, was regarded as a significant increase.

DETECTION OF VACCINE SPECIFIC ANTIBODIES IN GASTRIC ASPIRATES AND SERUM

Gastric aspirates were analysed for antitoxin and antibacterial IgA antibody titres by a GM1-CTB and a whole cell ELISA, respectively, and sera for IgA and IgG antitoxin titres by GM1-ELISA and IgG antibacterial titres by a vibriocidal assay. ${ }^{29}{ }^{30}$ In addition, the total IgA content in the gastric aspirates was determined by ELISA. Commercially available colostrum IgA standard (Sigma) was used as the reference. Gastric aspirates containing less than $20 \mu \mathrm{g} / \mathrm{ml}$ of IgA were excluded from the study as our previous studies have shown that samples with lower IgA concentrations do not give reproducible results. Serial dilutions of pre and post vaccination specimens were tested in duplicate, and the titre defined as the interpolated reciprocal dilution giving an absorbance of 0.4 above background. Gastric juice titres were adjusted for total $\operatorname{IgA}$ content in each sample. Significant titre increases were $\geqslant 2$-fold in ELISA and $\geqslant 4$-fold in vibriocidal assays. ${ }^{31}$

STATISTICAL ANALYSIS

Differences in inflammation and bacterial load between the study groups were evaluated by Wilcoxon rank sum test. The frequencies of responders in the different groups were evaluated using the hypothesis test for comparing independent proportions corrected for small sample sizes.

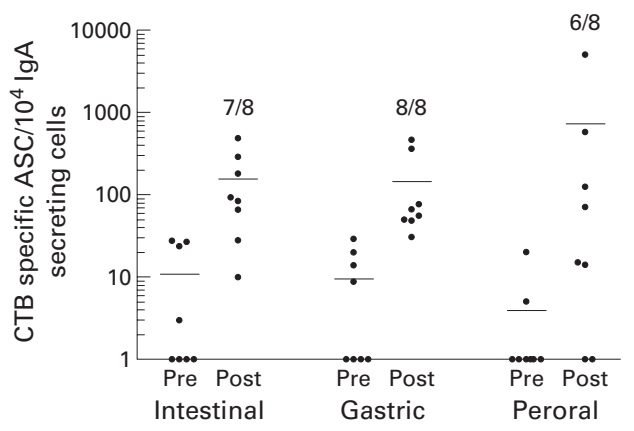

Figure 1 Duodenal antibody secreting cell (ASC) responses after intestinal, intragastric, or peroral immunisations. Duodenal biopsies were collected one week before and one week after a second immunisation with cholera vaccine, and IgA secreting $A S C$ reacting with cholera toxin B subunit (CTB) were detected by ELISPOT assays. Data are presented as individual frequencies of $C T B$ specific IgA secreting cells per $10^{4}$ total IgA secreting cells before (Pre) and after (Post) the respective immunisation regimens. Horizontal lines represent arithmetic mean. Numbers indicate the frequencies of responders in the respective groups.

\section{Results}

INFLAMMATION AND BACTERIAL LOAD

Biopsies from uninfected subjects were histologically normal without inflammation or HLO. In contrast, chronic inflammation and HLO were observed in biopsies from the antrum of all $H$ pylori infected volunteers. $H$ pylori was also cultured from antral biopsies from all infected subjects.

There was no significant difference in the inflammation in the antrum between the two groups of $H$ pylori infected subjects with a mean inflammatory score of $1.7(0.5)$ (mean $(\mathrm{SD}))$ in the intestinal immunisation group and $2.0(0)$ in the intragastric immunisation group. Furthermore, no significant changes in inflammation were recorded after immunisation.

ASC RESPONSES AFTER INTESTINAL

IMMUNISATION

One group of eight $H$ pylori infected individuals was immunised intestinally, and the frequencies of vaccine specific ASC were monitored in cell suspensions from the mucosal tissues and blood before and after immunisation. All but one volunteer responded to the immunisations with CTB specific IgA secreting cells in the duodenum $(\mathrm{p}<0.01$ compared with no responders). The mean increase in ASC frequencies among the responders was 60 -fold after vaccination (fig 1 ). Three subjects also responded with IgG secreting cells reacting with CTB. The specificity of the ASC responses obtained after immunisation was ascertained by parallel assays in BSA coated wells. Only one of the volunteers had low numbers of BSA reactive IgA secreting cells after immunisation.

Intestinal immunisation also resulted in induction of gastric CTB specific IgA secreting cells in five of eight vaccinees $(p<0.05)$, the mean increase being 19-fold in responding individuals (fig 2). Three of these volunteers also developed specific IgG ASC responses in the gastric mucosa although IgG responses were always lower than IgA responses. BSA 


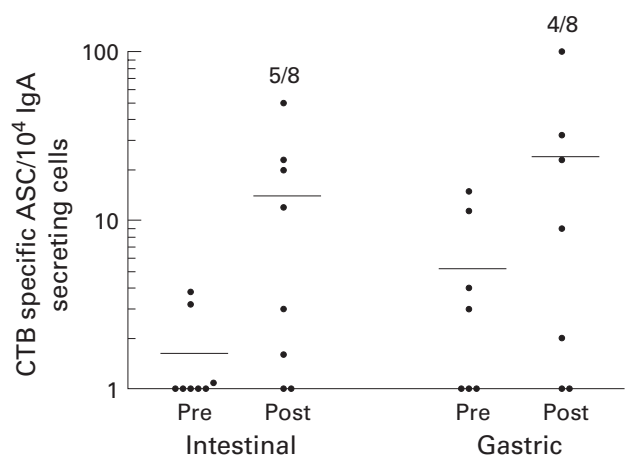

Figure 2 Gastric antibody secreting cell (ASC) responses after intestinal or intragastric immunisations. Gastric biopsies were collected one week before and one week after a second immunisation with cholera vaccine, and ASC reacting with cholera toxin $B$ subunit $(C T B)$ were detected by ELISPOT assays. Data are presented as individual frequencies of CTB specific IgA secreting cells per $10^{4}$ total IgA secreting cells before (Pre) and after (Post) the respective immunisation regimens. Horizontal lines represent arithmetic mean. One individual had very high levels of $C T B$ reactive $A S C$ at the first examination but only background levels after immunisation. However, as this subject had equally high levels of BSA reactive ASC before immunisation, the ASC observed in the preimmunisation specimen most likely represented non-specific reactions and hence data from this individual were not incorporated. Numbers indicate the frequencies of responders in the respective groups.

reactive ASC could not be detected in any of the volunteers.

Furthermore, intestinal immunisations gave rise to specific ASC responses against CTB in peripheral blood; all eight volunteers responded with circulating IgA secreting and seven with IgG secreting antitoxin ASC (fig 3).

ASC RESPONSES AFTER GASTRIC IMMUNISATION A second group of eight $H$ pylori infected volunteers received intragastric immunisations. Gastric antigen delivery resulted in induction of CTB specific IgA secreting cells in the gastric mucosa of four of eight volunteers, the

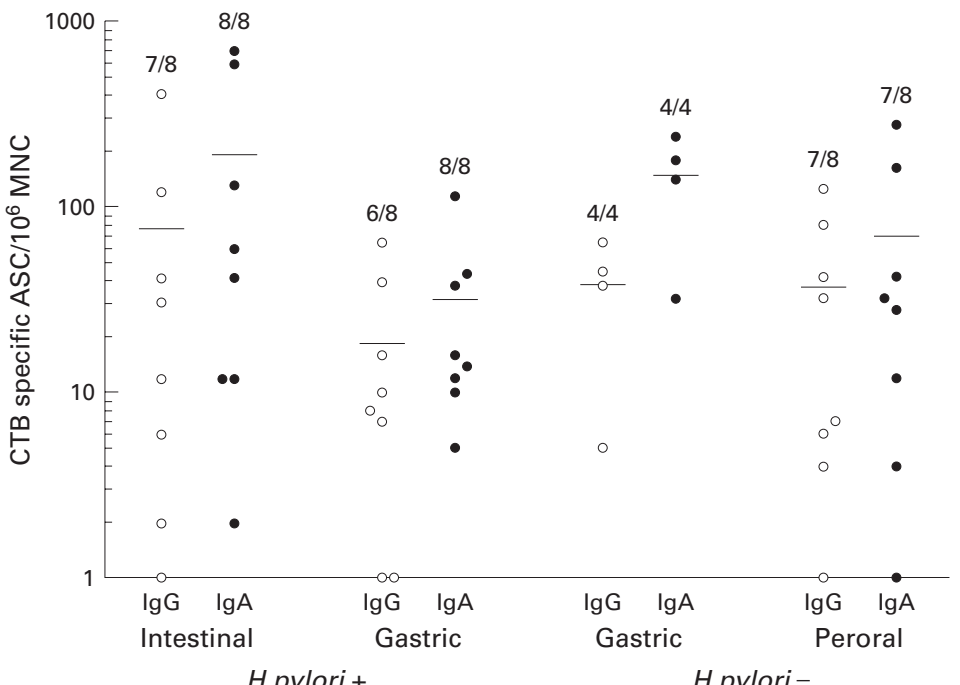

Figure 3 Circulating antibody secreting cell (ASC) responses after intestinal, intragastric, or peroral immunisation. Venous blood was collected before and after immunisation via the indicated routes and was analysed for the presence of cholera toxin B subunit (CTB) specific ASC in ELISPOT assays. Data are presented as individual frequencies of CTB specific IgG and IgA secreting cells before and after the respective immunisation regimens. Horizontal lines represent arithmetic mean. Numbers indicate the frequencies of responders in the respective groups. Vaccine specific ASC could not be detected before immunisation in any of the volunteers. mean increase being 12 -fold in responding subjects (fig 2). However, due to the small number of volunteers, this frequency of responders was not statistically significant. Two of the responding volunteers also had detectable frequencies of CTB specific IgG secreting cells, and none had BSA reactive ASC.

Gastric antigen delivery also gave rise to $\mathrm{B}$ cell responses in the proximal small intestine. Thus all volunteers had IgA secreting cells reacting with CTB in the duodenal mucosa $(\mathrm{p}<0.001)$ with a mean 120 -fold increase (fig 1), and three also had CTB specific IgG secreting cells. None of the volunteers had increased frequencies of BSA reactive ASC. As with the intestinally induced responses, all of the immunised volunteers had CTB specific IgA secreting cells in their circulation one week after the last gastric immunisation, and six also had IgG secreting cells reacting with CTB (fig 3).

To evaluate if gastric antigen delivery would induce local or disseminated B cell responses in uninfected volunteers also, an additional group of four uninfected volunteers underwent intragastric immunisation. These immunisations did not induce gastric ASC responses, except in one individual who had few CTB specific cells and was on the threshold level of having a significant response. Increased frequencies of CTB specific IgA secreting cells could be detected in the duodenal mucosa in two of the four uninfected volunteers. One of these individuals also had increased frequencies of IgG secreting cells reacting with CTB but none had increased frequencies of BSA reactive ASC. Circulating vaccine specific IgA and IgG ASC were observed in all of these individuals, in frequencies similar to those in the other experimental groups (fig 3).

ASC RESPONSES AFTER ORAL IMMUNISATION As a control group, $H$ pylori negative volunteers received two oral doses of cholera vaccine following a three day course of aspirin ingestion, in an attempt to create a mild gastric inflammation at the time of immunisation. As in our previous studies, ${ }^{22} 27$ this immunisation schedule resulted in increased frequencies of duodenal CTB specific ASC in the majority (six of eight; $\mathrm{p}<0.01$ ) of the volunteers one week after the second immunisation. The ASC response was dominated by $\operatorname{IgA}$ secreting cells (fig 1) whereas increased frequencies of CTB specific IgG secreting cells were only seen in one of the volunteers. In none of the volunteers was there any increase in BSA reactive ASC in the duodenum.

In contrast with the findings in the duodenum, and in keeping with our previous study, ${ }^{22}$ CTB specific ASC could not be detected in the gastric mucosa of these volunteers. Finally, the peripheral blood ASC response to CTB after oral immunisation was very similar to that obtained after intestinal vaccination, both in terms of responder frequency and isotype composition (fig 3). 
Table 1 Serum antitoxin and vibriocidal titres after immunisation with cholera vaccine by different routes

\begin{tabular}{|c|c|c|c|c|c|c|c|c|c|c|}
\hline \multirow[b]{2}{*}{ Immunisation } & \multirow[b]{2}{*}{$\begin{array}{l}\text { H pylori } \\
\text { status }\end{array}$} & \multicolumn{3}{|c|}{ Ig $A$ anti-CTB titres } & \multicolumn{3}{|c|}{ IgG anti-CTB titres } & \multicolumn{3}{|c|}{ Vibriocidal titres } \\
\hline & & Day 0 & Day 21 & $\begin{array}{l}\text { Frequency of } \\
\text { responders }\end{array}$ & Day 0 & Day 21 & $\begin{array}{l}\text { Frequency of } \\
\text { responders }\end{array}$ & Day 0 & Day 21 & $\begin{array}{l}\text { Frequency of } \\
\text { responders }\end{array}$ \\
\hline Intestinal & + & $\begin{array}{l}23 \\
(<5-361)\end{array}$ & $\begin{array}{l}423 \\
(121-2081)\end{array}$ & $6 / 8$ & $\begin{array}{l}92 \\
(18-432)\end{array}$ & $\begin{array}{l}562 \\
(191-2006)\end{array}$ & $5 / 8$ & $\begin{array}{l}23 \\
(<10-240)\end{array}$ & $\begin{array}{l}132 \\
(20-1920)\end{array}$ & $7 / 8$ \\
\hline Intragastric & + & $\begin{array}{l}44 \\
(8-438)\end{array}$ & $\begin{array}{l}433 \\
(237-1197)\end{array}$ & $6 / 8$ & $\begin{array}{l}78 \\
(30-316)\end{array}$ & $\begin{array}{l}447 \\
(94-2053)\end{array}$ & $7 / 8$ & $\begin{array}{l}14 \\
(<10-40)\end{array}$ & $\begin{array}{l}43 \\
(<10-640)\end{array}$ & $4 / 8$ \\
\hline Peroral & - & $\begin{array}{l}13 \\
(<5-80)\end{array}$ & $\begin{array}{l}151 \\
(<5-9228)\end{array}$ & $6 / 8$ & $\begin{array}{l}52 \\
(18-176)\end{array}$ & $\begin{array}{l}281 \\
(41-10935)\end{array}$ & $7 / 8$ & $\begin{array}{l}13 \\
(<10-80)\end{array}$ & $\begin{array}{l}60 \\
(<10-480)\end{array}$ & $5 / 8$ \\
\hline Intragastric & - & $\begin{array}{l}18 \\
(10-50)\end{array}$ & $\begin{array}{l}830 \\
(150-3790)\end{array}$ & $4 / 4$ & $\begin{array}{l}32 \\
(10-70)\end{array}$ & $\begin{array}{l}736 \\
(120-4340)\end{array}$ & $4 / 4$ & $\begin{array}{l}<10 \\
(<10-<10)\end{array}$ & $\begin{array}{l}95 \\
(<10-640)\end{array}$ & $3 / 4$ \\
\hline
\end{tabular}

Data are presented as geometric mean (range).

CTB, cholera toxin B subunit.

ANTIBODY RESPONSES IN SERUM

Twenty four of 28 subjects responded to the vaccination with significantly increased levels of anti-CTB (IgA, IgG, or both) antibodies in serum (table 1). Nineteen of the 28 volunteers also responded with increased vibriocidal titres after immunisation (table 1). There was no significant difference in antibody responses in serum among the four groups of immunised volunteers.

ANTIBODY RESPONSES IN GASTRIC ASPIRATES

Four of eight $H$ pylori infected volunteers receiving intestinal immunisation and four of eight given intragastric immunisation had increased levels of CTB specific IgA in gastric juice. Only two of five subjects who received peroral immunisation and one of four healthy volunteers who received intragastric immunisation had increased titres of gastric CTB specific IgA. Furthermore, two of eight intestinally immunised, two of five perorally immunised, and four of 12 intragastrically immunised volunteers had increased gastric titres against whole vibrios (table 2). Due to low total IgA concentrations, samples from only five of eight volunteers who received peroral immunisation could be analysed.

\section{Discussion}

According to the generally accepted concept of a common mucosal immune system, B cell immunoblasts activated in organised mucosal inductive sites migrate via the blood to their final destination, mainly the intestinal lamina propria, but also to remote mucosal tissues and exocrine glands. ${ }^{32}{ }^{33} \mathrm{~A}$ number of studies have indicated a certain degree of compartmentalisation of immune responses within mucosa associated lymphoid tissues, ${ }^{34-38}$ in the sense that cells activated in a certain tissue tend to migrate back to mucosal surfaces close to their original site of activation. This study therefore examined whether gastric B cell responses can be induced by distant intestinal immunisation or by local intragastric immunisation. Our results demonstrated that a strictly intestinal antigen administration can result in accumulation of vaccine specific IgA secreting cells in the gastric mucosa of $H$ pylori infected individuals. This provides evidence for migration of circulating lymphocytes into the gastric mucosa with $H$ pylori associated gastritis. In contrast, we have previously shown that there is no detectable migration of circulating $\mathrm{B}$ cell blasts to uninfected healthy gastric mucosa, ${ }^{22}$ a finding that was confirmed in the present study. In this study, healthy volunteers were treated with acetylsalicylic acid to induce gastric inflammation at the time of antigen delivery but this treatment could not revert the non-responsiveness of the uninfected stomach. Therefore, $H$ pylor $i$ infected but not uninfected human stomach appears to be part of the generalised mucosal immune network.

It could be argued that the B cell responses recorded in the stomach after intestinal immunisations were caused by antigen reflux from the proximal small intestine to the stomach but there are several reasons to believe that this was not the case. The high binding capacity of CTB to ganglioside GM1, which is present on all nucleated cells, probably results in rapid capture of all CTB in the vaccine. Furthermore, any CTB reaching the acid gastric milieu would rapidly dissociate into nonimmunogenic monomers. Finally, significant reflux of antigens from the small intestine to the stomach could not be observed, either by visual inspection or by measuring vaccine

Table 2 Gastric juice antitoxin and anti-whole cell titres after immunisation with cholera vaccine by different routes

\begin{tabular}{|c|c|c|c|c|c|c|c|}
\hline \multirow[b]{2}{*}{ Immunisation } & \multirow[b]{2}{*}{$\begin{array}{l}\text { H pylori } \\
\text { status }\end{array}$} & \multicolumn{3}{|c|}{ IgA anti-CTB titres } & \multicolumn{3}{|c|}{ IgA anti-whole cell titres } \\
\hline & & Day 0 & Day 21 & $\begin{array}{l}\text { Frequency of } \\
\text { responders }\end{array}$ & Day 0 & Day 21 & $\begin{array}{l}\text { Frequency of } \\
\text { responders }\end{array}$ \\
\hline Intestinal & + & $\begin{array}{l}0.17 \\
(0.025-0.92)\end{array}$ & $\begin{array}{l}0.44 \\
(0.061-4.2)\end{array}$ & $4 / 8$ & $\begin{array}{l}1.2 \\
(0.09-9.9)\end{array}$ & $\begin{array}{l}0.82 \\
(0.12-10.0)\end{array}$ & $2 / 8$ \\
\hline Intragastric & + & $\begin{array}{l}0.14 \\
(0.006-1.9)\end{array}$ & $\begin{array}{l}0.22 \\
(0.027-1.6)\end{array}$ & $4 / 8$ & $\begin{array}{l}0.95 \\
(0.22-3.6)\end{array}$ & $\begin{array}{l}0.78 \\
(0.20-2.5)\end{array}$ & $3 / 8$ \\
\hline Peroral & - & $\begin{array}{l}0.15 \\
(0.033-0.49)\end{array}$ & $\begin{array}{l}0.27 \\
(0.12-10.3)\end{array}$ & $2 / 5$ & $\begin{array}{l}12.0 \\
(0.28-40.1)\end{array}$ & $\begin{array}{l}5.2 \\
(0.075-149)\end{array}$ & $2 / 5$ \\
\hline Intragastric & - & $\begin{array}{l}0.43 \\
(0.18-0.75)\end{array}$ & $\begin{array}{l}0.22 \\
(0.080-1.5)\end{array}$ & $1 / 4$ & $\begin{array}{l}0.70 \\
(0.56-1.0)\end{array}$ & $\begin{array}{l}1.8 \\
(0.38-53.1)\end{array}$ & $1 / 4$ \\
\hline
\end{tabular}

Data are presented as geometric mean (range) of the specific titre divided by the total concentration of $\operatorname{IgA}(\mu \mathrm{g} / \mathrm{ml})$ in the respective samples.

CTB, cholera toxin B subunit. 
components in gastric aspirates collected after immunisations.

This study also showed that gastric antigen delivery induced a disseminated response that could be detected in blood and in the small intestine of most volunteers, irrespective of whether or not they were $H$ pylori infected. Therefore, the human stomach mucosa may be able to serve as an inductive site for generalised mucosal responses against intragastrically administered antigens although we cannot fully rule out the possibility that some of the antigens delivered to the gastric mucosa may have reached intestinal inductive sites. If the intragastrically delivered antigens were indeed taken up through the gastric epithelium, they may have been presented locally in the gastric mucosa, in regional mesenteric lymph nodes, or even in other lymphoid tissues. But even though gastric antigen delivery resulted in circulating B cell responses in all volunteers, only $H$ pylori infected individuals had gastric ASC after such immunisations. This again suggests that gastric B cell responses are accomplished mainly by migration of plasma cell precursors from the circulation in $H$ pylori infected individuals rather than by local gastric activation and differentiation of naive $B$ cells. Increased migration of $\mathrm{B}$ cells into the gastric mucosa probably also contributes to the large accumulation of IgA secreting cells (about 10\% of all MNC), of which many are specific for $H$ pylori antigens, in the gastric mucosa of $\mathrm{H}$ pylori infected individuals. ${ }^{8}$

Based on our results, a therapeutic vaccine against $H$ pylori does not necessarily have to be delivered directly to the gastric mucosa but could probably rely on migration of specific effector lymphocytes to the stomach. In support of this notion, a recent study by Michetti and colleagues ${ }^{39}$ showed that protective immunity after prophylactic immunisation against $H$ felis is dependent on migration of circulating lymphocytes to mucosal tissues. Furthermore, peroral, rectal, and intranasal immunisations all result in protective immunity against $H$ pylori challenge in a murine model. ${ }^{40}$ In humans however nasal antigen delivery does not seem to be an efficient way to induce intestinal antibody responses. ${ }^{37} 41$ Preliminary results from our laboratory indicate that the same is also true for gastric B cell responses after nasal immunisation (E-L Johansson, C Bergquist et al, manuscript in preparation).

The increased lymphocyte migration to the $H$ pylori infected stomach is probably dependent on production of inflammatory chemokines. Thus $H$ pylori infection results in increased production of macrophage inflammatory protein $1 \alpha(\mathrm{MIP}-1 \alpha)$, growth related oncogene $\alpha$ (GRO- $\alpha$ ), and RANTES, as well as $B$ cell attracting chemokine 1 (BCA-1) in the gastric mucosa. ${ }^{42-44}$ Another factor that probably influences the possibility of circulating lymphocytes to enter the infected, but not the uninfected, gastric mucosa is increased expression of some endothelial adhesion molecules in the stomach of $H$ pylori infected individuals. ${ }^{456}$ Thus $H$ pylori infection results in increased endothelial expression of intercellular adhesion molecule 1 and vascular cell adhesion molecule 1 , and a slower rolling of leucocytes over endothelial cells in gastric venules. Upregulation of adhesion molecules is probably caused by increased local production of cytokines such as interferon $\gamma$ and tumour necrosis factor $\alpha$ in response to infection ${ }^{47-51}$ as these cytokines are potent inducers of endothelial adhesion molecule expression. ${ }^{52}$ Furthermore, mucosal venules in the stomach express the mucosal addressin cellular adhesion molecule $1^{53}$ which is also abundant in the intestinal mucosa. ${ }^{54}$ Therefore, similar recognition events might determine lymphocyte extravasation in the small intestine and in the $H$ pylori infected stomach, events that may facilitate lymphocyte trafficking to the inflamed gastric mucosa after intestinal immunisation.

In conclusion, this study suggests that $H$ pylori infection alters the capacity of the gastric mucosa to serve as an expression site for intestinally induced B cell responses by increasing the recruitment of effector lymphocytes. Our results also suggest that the stomach might function as an inductive site for disseminated ASC responses although this has to be further confirmed in future experiments. Our findings in this study have obvious implications in the efforts to design a therapeutic $H$ pylori vaccine for human use, and based on these results such a vaccine might be delivered to the proximal small intestine and not directly to the gastric mucosa.

We thank all volunteers who participated in this study. We are grateful to Dr Annika Hamlet for valuable help with recruitment of volunteers, and Dr Anna Mattsson, Dr Catharina Lindholm, Camilla Johansson, Marie Bengtsson, and the staff at the gastroenterological department at Sahlgrenska University Hos-
pital for their technical assistance and generous help. This study pital for their technical assistance and generous help. This study was supported by the Swedich Medical Research Council (grant No 16X-13055), the Swedish Foundation for Strategic Research and by a grant from AstraZeneca Research Center, Boston, Massachusetts, USA.

1 Parsonnet J, Hansen S, Rodriguez L, et al. Helicobacter pylori infection and gastric lymphoma. N Engl $\mathcal{F}$ Med infection and gas

2 Peek RM, Blaser MJ. Pathophysiology of Helicobacter pylori induced gastritis and peptic ulcer disease. Am F Med 1997; 102:200-7.

3 Genta RM, Gurer IE, Graham DY. Gastric lymphoid follicles in Helicobacter pylori infection: frequency, distribuion, and response to triple therapy. Hum Pathol 1993;24: 577-83.

4 Luzza F, Imeneo $M$, Maletta $M$, et al. Isotypic analysis of specific antibody response in serum, saliva, gastric and rectal homogenates of Helicobacter pylori-infected patients. FEMS Immunol Med Microbiol 1995;10:285-8.

5 Wyatt JI, Rathbone BJ. Immune response of the gastric mucosa to Campylobacter pylori. Scand $\mathcal{f}$ Gastroenterol Suppl 1988;142:44-9.

6 Veenendaal RA, Götz JM, Schroijen V, et al. Diagnosis of Helicobacter pylori infection by specific gastric mucosal IgA Helicobacter pylori infection by specific gastric mucosal IgA

7 Mattsson A, Tinnert A, Hamlet A, et al. Specific antibodies in sera and gastric aspirates of symptomatic and asymptomatic Helicobacter pylori infected subjects. Clin Diagnost Lab Immunol 1998;5:288-93.

8 Mattsson A, Quiding-Järbrink $\mathrm{M}$, Lönroth $\mathrm{H}$, et al. Antibody-secreting cells in the stomach of symptomatic and asymptomatic Helicobacter pylori infected subjects. Infect Immun 1998;66:2705-12.

9 Marchetti M, Arico B, Burroni D, et al. Development of a mouse model of Helicobacter pylori infection that mimics human disease. Science 1995;267:1655-8.

10 Ferrero RL, Thiberge J-M, Kansau I, et al. The GroES homolog of Helicobacter pylori confers protective immunity against mucosal infection in mice. Proc Natl Acad Sci USA 1995;92:6499-503.

11 Michetti P, Corthesy-Theulaz I, Davin C, et al. Immunisation of BALB/c mice against Helicobacter felis infection with H. pylori urease. Gastroenterology 1994;107:1002-11.

12 Lee CK, Weltzin R, Thomas Jr WD, et al. Oral immunisation with recombinant Helicobacter pylori urease induces secretory IgA antibodies and protects mice from challenge with Helicobacter felis. F Infect Dis 1995;172:161-72. 
13 Pappo J, Thomas Jr WR, Kabok Z, et al. Effect of oral Pacter felis gastitis. Gastrenterology 1995;63:1246- 52 . bacter felis gastritis. Gastroenterology 1995;63:1246-52.

14 Ferrero RL, Thiberge J-M, Labigne A. Local immunoglobulin $G$ antibodies in the stomach may contribute to immunity against Helicobacter infection in mice. Gastroen terology 1997;113:185-94

15 Corthesy-Theulaz I, Porta N, Glauser M, et al. Oral immunisation with Helicobacter pylori urease B subunit as a treatment against Helicobacter infection in mice. Gastroenterology 1995;109:115-21.

16 Doidge P, Gust I, Lee A, et al. Therapeutic immunisation against Helicobacter infection. Lancet 1994;343:914-15.

17 Ghiara P, Rossi M, Marchetti M, et al. Therapeutic intragastric vaccination against Helicobacter pylori in mice eradicates an otherwise chronic infection and confers protection against reinfection. Infect Immun 1997;65:4996tection 5002 .

18 Thomas JE, Austin S, Dale A. Protection by human milk IgA against Helicobacter pylori infection in infancy. Lancet IgA against $H$.

19 Czinn SJ, Cai A, Nedrud JG. Protection of germ-free mice from infection by Helicobacter felis after active oral or passive

20 Blanchard TG, Czinn SJ, Maurer R, et al. Urease specific monoclonal antibodies prevent Helicobacter felis infection in mice. Infect Immun 1995;63:1394-9.

21 Ermak TH, Giannasca PJ, Nichols R, et al. Immunisation of mice with urease vaccine affords protection against Helicobacter pylori infection in the absence of antibodies and is mediated by MHC class II-restricted responses. 7 Exp Med 1998;188:2277-88.

22 Mattsson A, Lönroth $\mathrm{H}$, Quiding-Järbrink $\mathrm{M}$, et al. Induction of $\mathrm{B}$ cell responses in the stomach of Helicobacter pylori-infected subjects after oral cholera vaccination. $\mathcal{F}$ Clin Invest 1998;102:51-6.

23 Hamlet AK, Erlandsson KIM, Olbe L, et al. A simple, rapid and highly reliable capsule-based $14 \mathrm{C}$ urea breath test for diagnosis of $H$. pylori infection. Scand $\mathcal{7}$ Gastroenterol 1995; diagnosis of

24 Holmgren J, Svennerholm A-M, Jertborn M, et al. An oral B subunit: whole cell vaccine against cholera. Vaccine 1992:10:911-14.

25 Hamlet A, Lindholm C, Nilsson O, et al. Aspirin-induced gastritis, like Helicobacter pylori-induced gastritis, disinhibits acid secretion in humans: relation to cytokine expression. Scand F Gastroenterol 1997; 33: 346-56.

26 Dixon MF, Genta RM, Yardley JH, et al. Classification and grading of gastritis. The upgraded Sydney System. International Workshop on the Histopathology of Gastritis. Am f Surg Pathol 1996;20:1161-81.

27 Quiding M, Nordström I, Kilander A, et al. Intestinal immune responses in humans. Oral cholera vaccination induces strong intestinal antibody responses and interferon-gamma production and evokes local immunological memory. F Clin Invest 1991;88:143-8.

28 Czerkinsky C, Moldoveanu Z, Mestecky J, et al. A novel two-colour ELISPOT assay. I: Simultaneous detection of two-colour ELISPOT assay. I: Simultaneous detection of
distinct types of antibody-secreting cells. $\mathcal{F}$ Immunol distinct types of antibod

29 Jertborn M, Svennerholm A-M, Holmgren J. Intestinal and systemic immune responses in humans after oral immunisation with a bivalent B subunit-O1/O139 whole cell cholera vaccine. Vaccine 1996;14:1459-65

30 Svennerholm A-M, Holmgren J, Black R, et al. Serologic differentiation between antitoxin responses to infection with Vibrio cholerae and enterotoxin-producing Escherichia coli. F Infect Dis 1983;147:514-22.

31 Jertborn M, Svennerholm A-M, Holmgren J. Safety and immunogenicity of an oral recombinant cholera B subunitwhole cell vaccine against cholera. Vaccine 1992;10:130-2

32 Mestecky J. The common mucosal immune system and current strategies for induction of immune responses in external secretions. F Clin Immunol 1987; 7:265-76.

33 McGhee JR, Mestecky J, Dertzbaugh MT, et al. The mucosal immune system: from fundamental concepts to vaccine development. Vaccine 1992;10:75-88.

34 Nadal D, Albini B, Schläpfer E, et al. Tissue distribution of mucosal antibody-producing cells specific for respiratory cyncytial virus in severe combined immunodeficiency (SCID) mice engrafted with human tonsils. Clin Exp

35 Haneberg B, Kendall D, Amerongen HM, et al. Induction of specific immunoglobulin $\mathrm{A}$ in the small intestine, colonrectum, and vagina measured by a new method for collection of secretions from local mucosal surfaces. Infect Immun 1994;62:15-23.

36 Hopkins S, Kraehenbuhl J-P, Schödel F, et al. A recombinant Salmonella typhimurium vaccine induces local immunity by four different routes of immunisation. Infect Immun 1995;63:3279-86.

37 Quiding-Järbrink M, Granström G, Nordström I, et al. Induction of compartmentalised B cell responses in human tonsils. Infect Immun 1995;63:853-7.

38 Eriksson K, Quiding-Järbrink M, Osek J, et al. Anatomical segmentation of the intestinal immune response in non-human primates: Evidence for differential distribution of $B$ cells to sites defined by their source of vascularisation. Infect Immun 1999;67:6210-12.

39 Michetti M, Kelly CP, Kraehenbuhl J-P, et al. Gastric mucosal $\alpha 4 \beta 7$-integrin-positive CD4 $\mathrm{T}$ lymphocytes and immune protection against Helicobacter infection in mice.

40 Kleanthous H, Myers GA, Georgakopoulos KM, et al. Rectal and intranasal immunizations with recombinant urease induce distinct local and serum immune responses in mice and protect against Helicobacter pylori infection. Infect Immun 1998;66:2879-86.

41 Bergquist C, Johansson E-L, Lagergård T, et al A. Intranasal vaccination of humans with recombinant cholera toxin $B$ subunit induces systemic and local antibody responses in the upper respiratory tract and the vagina. Infect Immun 1997;65:2676-84

42 Yamaoka Y, Kita M, Kodama T, et al. Expression of chemokine mRNA in gastric mucosa with Helicobacter pylori infection. Gastroenterology 1996;110:A1049.

43 Shimoyama T, Everett SM, Dixon MF, et al. Chemokine mRNA expression in gastric mucosa is associated with Helicobacter pylori cagA positivity and severity of gastritis. 7 Clin Pathol 1998;51:765-70.

44 Mazzucchelli L, Blaser A, Kappeler A, et al. BCA-1 is highly expressed in Helicobacter pylori-induced mucosa-associated ymphoid tissue and gastric lymphoma. F Clin Invest 1999; 104:R49-4

45 Hatz RA, Rieder G, Stolte M, et al. Pattern of adhesion molecule expression on vascular endothelium in Helicobacter pylori-associated antral gastritis. Gastroenterology 1997;112: 1908-19.

46 Elizalde JI, Gomez J, Panes J, et al. Platelet activation in mice and human Helicobacter pylori infection. F Clin Invest 1997; 100:996-1005.

47 Crabtree JE, Shallcross TM, Heatley RV, et al. Mucosal tumour necrosis factor alpha and interleukin- 6 in patients with Helicobacter pylori associated gastritis. Gut 1991;32: 1473-7.

48 D'Elios MM, Manghetti M, De Carli M, et al. T helper 1 effector cells specific for Helicobacter pylori in the gastric antrum of patients with peptic ulcer disease. 7 Immunol 1997;158:962-7.

49 Karttunen R, Karttunen T, Ekre H-P, et al. Interferon gamma and interleukin 4 secreting cells in the gastric antrum in Helicobacter pylori positive and negative gastritis. Gut 1995;36:341-5

50 Moss SF, Legon S, Davies J, et al. Cytokine gene expression in Helicobacter pylori associated antral gastritis. Gut 1994;35:1567-70.

51 Lindholm C, Quiding-Järbrink $M$, Lönroth $\mathrm{H}$, et al. Local cytokine response in Helicobacter pylori-infected subjects. Infect Immun 1998;66:5964-71.

52 Boehm U, Klamp T, Groot M, et al. Cellular responses to interferon-gamma. Annu Rev Immunol 1997;15:749-95.

53 Dogan A, Du M, Koulis A, et al. Expression of lymphocyte homing receptors and vascular addressins in low-grade gastric B-cell lymphomas of mucosa-associated lymphoid tissue. Am f Pathol 1997;151:1361-9.

54 Springer TA. Traffic signals for lymphocyte recirculation and leukocyte emigration: the multistep paradigm. Cell 1996;76:301-8. 